\title{
Harcourt - Le château : porte Piquet
}

$\mathrm{n}^{\circ} 17-2288$

\section{Gilles Deshayes}

\section{(2) OpenEdition}

Journals

Édition électronique

URL : http://journals.openedition.org/adlfi/16580

ISSN : 2114-0502

Éditeur

Ministère de la culture

Référence électronique

Gilles Deshayes, « Harcourt - Le château : porte Piquet », ADLFI. Archéologie de la France - Informations [En ligne], Haute-Normandie, mis en ligne le 18 février 2016, consulté le 03 mai 2019. URL : http:// journals.openedition.org/adlfi/16580

Ce document a été généré automatiquement le 3 mai 2019.

(c) Ministère de la Culture et de la Communication, CNRS 


\title{
Harcourt - Le château : porte Piquet
}

$n^{\circ} 17-2288$

\author{
Gilles Deshayes
}

Code INSEE commune : 27311

Lien Atlas (MCC) :

http://atlas.patrimoines.culture.fr/atlas/trunk/index.php?

ap_theme=DOM_2.01.02\&ap_bbox=0.727;49.146;0.820;49.186

1 La porte nord de la basse-cour du château d'Harcourt, dite Porte Piquet, était défendue par une barbacane et de puissants fossés, le plus proche de cette dernière étant franchissable par un pont dormant. Elle était composée d'un couloir axial, de deux tours de flanquement, encadrées de courtines contre lesquelles étaient adossés des grands édifices.

2 Le diagnostic, en amont d'un projet de restauration, a mis en évidence deux états successifs, comportant pour chacun un couloir a priori de même largeur, deux tours de flanquement, deux courtines d'un même tracé et probablement aussi deux bâtiments identiques adjacents. Du premier au second état, la construction monumentale est passée d'un mortier jaune à un mortier orange, a varié l'épaisseur de certains murs, conservé la largeur du couloir et a priori augmenté la taille des tours (seuls les vestiges primitifs de la tour ouest ont été pour l'instant observés). Sous réserve, le premier état de ces constructions pourrait dater de la fin du XII ${ }^{\mathrm{e}}$ ou de la première moitié du XIII ${ }^{\mathrm{e}} \mathrm{s}$. ; le second état serait attribuable à la fin du XIII ${ }^{\mathrm{e}} \mathrm{s}$. ou au courant du $\mathrm{XIV}^{\mathrm{e}} \mathrm{s}$. Le mobilier datant fait défaut, notamment en raison d'une fouille limitée aux remblais postérieurs.

Entre ces deux chantiers de construction, les bâtiments subissent un incendie suivi d'une importante démolition. Une fois reconstruits, à plus ou moins long terme, ils sont dotés d'un pavage de silex (couloir), d'une cheminée (bâtiment est), d'enduits muraux en plâtre (bâtiment ouest), et d'un emmarchement sous une archère (tour est). Le passage entre les deux tours est réduit par la mise en place d'un épais mur, puis définitivement condamné par des pierres en vrac, liées de torchis. Tous ces bâtiments sont détruits au cours de l'époque moderne et leurs débris étalés et nivelés. 
Quelques observations ont permis de localiser et d'identifier dans le fossé de la hautecour les pans subsistants du glacis de la contrescarpe, les restes d'une hypothétique tour dans l'angle nord-est de la basse-cour et les ruines d'un mur ou d'un glacis appuyé contre le talus séparant le fossé de la haute-cour de celui de la basse-cour.

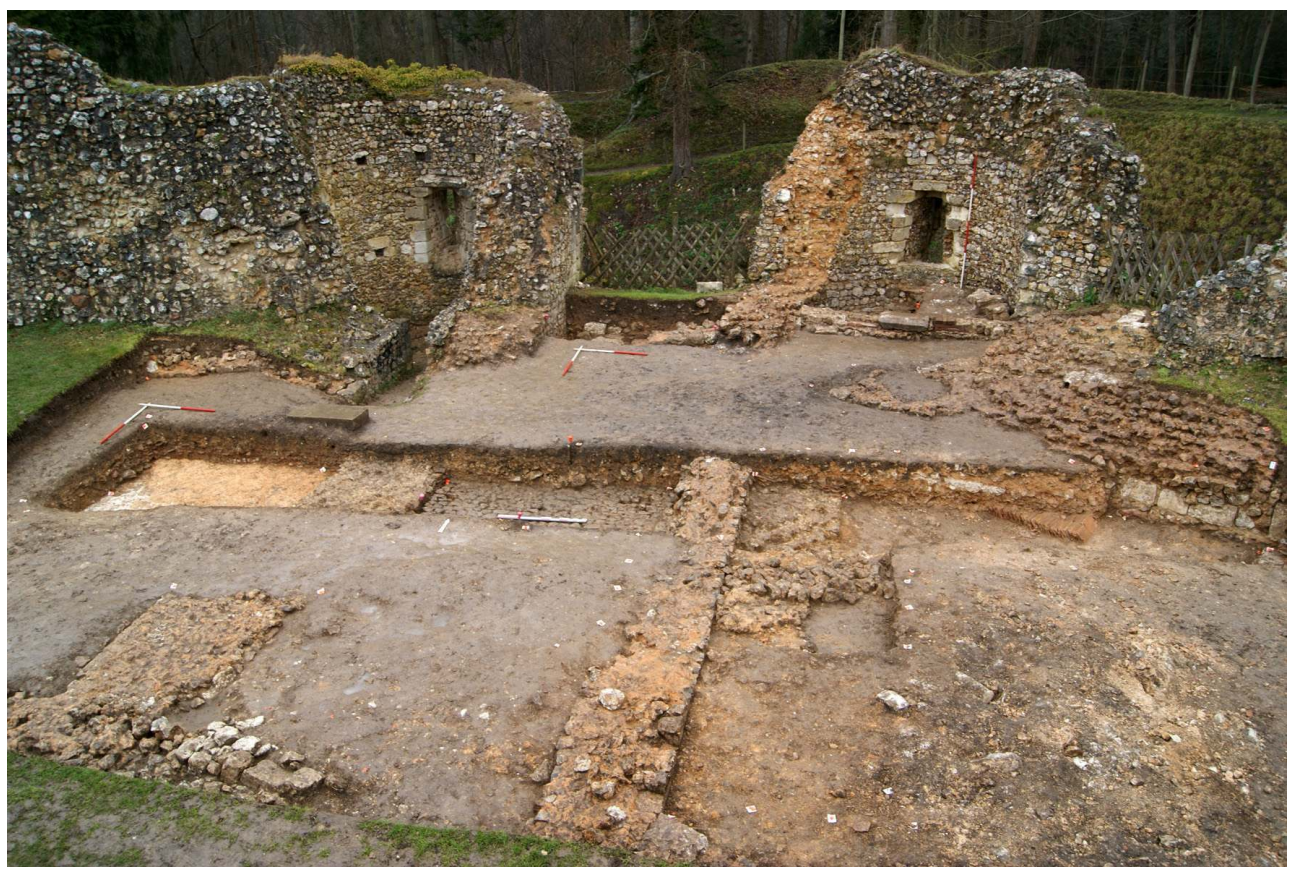

Fig. 01

Vue d'ensemble du sondage

G. Deshayes

INDEX

Index chronologique : Moyen Âge

operation Diagnostic (EV)

Index géographique : Normandie, Eure (27), Harcourt

Mots-clés : château, fortification, mur d'enceinte, porte, pont dormant, tour, incendie, fossé

\section{AUTEURS}

\section{GILLES DESHAYES}

Mission Archéologique de l'Eure 